\title{
DOENÇAS PRÉ E PÓS-COLHEITA EM VARIEDADES DE MANGA CULTIVADAS EM SISTEMA ORGÂNICO ${ }^{1}$
}

\author{
JULIANA ALTAFIN GALLI², IVAN HERMAN FISCHER ${ }^{3}$, \\ MARIA CECÍLIA DE ARRUDA PALHARINI ${ }^{3}$
}

RESUMO - A escolha da variedade de manga a ser plantada em sistema orgânico de produção deve estar relacionada com as limitações fitossanitárias. Assim, o objetivo do presente trabalho foi avaliar o comportamento de variedades de manga cultivadas em sistema orgânico frente às doenças: malformação floral, oídio e doenças pós-colheita dos frutos. Foram avaliadas 17 variedades, cultivadas em sistema orgânico, plantadas em delineamento experimental em blocos completos ao acaso, com 17 tratamentos e seis repetições. A incidência de malformação floral foi determinada através da observação e contagem das plantas com sintomas da doença. Para avaliar a severidade de malformação e de oídio, foram utilizadas escalas de notas. Para a caracterização das doenças pós-colheita, a severidade da antracnose foi visualmente avaliada após 1, 4, 7 e 10 dias da colheita dos frutos. Após a obtenção dos dados, foi calculada a área abaixo da curva de progresso da doença (AACPD). Pode-se concluir que a variedade Rosa é muito resistente à malformação floral; as variedades Bourbon, Espada Stahl, Ataulfo e Beta podem ser classificadas como resistentes, e a variedade Lita é a mais afetada pela doença dentre as variedades estudadas. As variedades Omega e Rocha podem ser consideradas como resistentes ao oídio, e as variedades Espada Ouro de Itaparica, Imperial, Lita, Rosa e Ubá são as mais suscetíveis. A ocorrência de doenças pós-colheita foi elevada na maioria das variedades de manga, sendo a antracnose a doença mais frequente, afetando os frutos a partir do primeiro dia de armazenamento, seguida pela podridão peduncular com ocorrência importante ao final do armazenamento. As variedades Bourbon Vermelha e Espada Stahl destacam-se por não apresentar podridão peduncular e menor severidade de antracnose.

Termos para indexação: Mangifera indica; oídio; malformação floral; antracnose; podridão peduncular.

\section{PRE AND POST-HARVEST DISEASES IN MANGO VARIETIES CULTIVATED IN ORGANIC SYSTEM}

\begin{abstract}
The choice of mango variety to be used in an organic production system should be related with phytosanitary limitations, thus the objective of the present study was to evaluate the behavior of mango varieties cultivated in organic system in relation to the diseases powdery mildew, flower malformation and post harvest diseases. Seventeen mango varieties were evaluated, cultivated in organic system, planted in experimental design in randomized blocks, with 17 treatments and six repetitions. The incidence of flower malformation was determinate through the observation and count of the plants with symptoms of the disease. To evaluate the severity of malformation and powdery mildew were used scales of notes. For the characterization of the post-harvest diseases the severity of the anthracnose was visually evaluated after 1, 4, 7 and 10 days of the fruits harvest. After obtaining the data, the area under the disease progress (AUDP) was calculated. It can be concluded that the Rosa variety is very resistant to the flower malformation; the varieties Bourbon, Espada Stahl, Ataulfo and Beta can be classified as resistant and the variety Lita is the most affected for the disease among the studied varieties. The varieties Omega and Rocha can be considered as resistant to the powdery mildew and the varieties Espada Ouro de Itaparica, Imperial, Lita, Rosa and Ubá are the most susceptible. The occurrence of post-harvest diseases was elevated in most of the mango varieties, being the anthracnose the most frequent one, affecting the fruits starting from the first day of storage, followed for the stem-end rot with important occurrence at the end of the storage. The varieties Bourbon Vermelha and Espada Stahl stand out for not presenting stem-end rot and smaller anthracnose severity.
\end{abstract}

Index terms: Mangifera indica; powdery mildew; flower malformation; anthracnose; stem-end rot.

\footnotetext{
${ }^{1}$ (Trabalho 050-12). Recebido em: 09-01-2012. Aceito para publicação em: 10-08-2012.

${ }^{2}$ Pesquisador Científico APTA Centro Norte, Cx Postal 24, 15830-000, Pindorama-SP. E-mail: julianagalli@apta.sp.gov.br ${ }^{3}$ Pesquisador Científico APTA Centro Oeste, Av. Rodrigues Alves, 40-40, 17030-000, Bauru-SP. E-mails: ihfische@apta.sp.gov.br; mcarruda@apta.sp.gov.br
} 


\section{INTRODUÇÃO}

A fase de florescimento e desenvolvimento inicial do fruto é um período crucial na produção comercial de manga, uma vez que diversos fatores podem provocar perdas severas na produção, como as doenças oídio, malformação floral e antracnose. A intensidade de ocorrência de cada uma das enfermidades está intimamente relacionada com o clima no período, principalmente sob a ação da umidade relativa do ar, que, em condições elevadas, favorece o ataque de antracnose e, em baixas, a ocorrência de oídio (KAVATI, 2004).

O oídio, causado pelo fungo Oidium mangiferae Bert., foi primeiramente reportado no Brasil em 1914, e subsequentemente reportado em vários outros países. É caracterizado por um pó branco (micélio) sobre as partes doentes. Os frutos afetados não crescem e podem cair antes de atingir o tamanho de uma ervilha. As perdas causadas por este patógeno podem superar os 20\% (NOFAL; HAGGAG, 2006), havendo também diferenças de suscetibilidade entre as variedades (RIBEIRO, 2005).

A malformação da mangueira é uma séria doença em áreas tropicais e subtropicais do mundo e tem sido atribuída a várias espécies de Fusarium, incluindo F. mangiferae, F. proliferatum, F. sacchari, F. sterilihyphosum e F. subglutinans. (LIMA et al., 2009). Os sintomas principais de malformação na inflorescência incluem panículas ramificadas de forma anormal e panículas grossas que produzem até três vezes o número normal de flores. Estas flores são aumentadas, estéreis e não produzem frutos (MARASAS et al., 2006; YOSSEF et al., 2007). Não há informações acuradas das perdas de rendimento causadas pela malformação da mangueira na maioria dos países produtores. Estimam-se perdas entre 50 a $80 \%$ nas cultivares suscetíveis, na Índia (KUMAR et al., 2011). A suscetibilidade das variedades Tommy Atkins e Keitt à malformação, tem levado pomares à erradicação (RIBEIRO, 2005).

Dentre as várias doenças em pós-colheita da manga, a mais importante é a antracnose, causada por Colletotrichum gloeosporioides Penz, seguida pela podridão peduncular, causada por um complexo de fungos, sendo Fusicoccum spp. e Lasiodiplodia theobromae (Pat.) Griffon \& Maubl. os mais comuns em climas úmidos e quentes (RIBEIRO, 2005). A antracnose afeta todos os órgãos da planta, mas o prejuízo maior é causado nos frutos, onde aparecem manchas escuras irregulares na casca, que podem coalescer, envolvendo grandes áreas do fruto. A podridão peduncular caracteriza-se por uma podridão marrom-escura, com bordas bem definidas, começando pela região peduncular, local de penetração do patógeno (ANGEL et al., 2006).

No controle das doenças que ocorrem na cultura da mangueira, normalmente, são observados o uso abusivo de agrotóxicos e a agressividade crescente dos patógenos. Nas regiões de clima favorável à antracnose, a primeira pulverização é geralmente efetuada antes do florescimento, com pulverizações a cada 15 a 20 dias, até a frutificação (ZAMBOLIM; JUNQUEIRA, 2004). Dessa forma, variedades que apresentam boa produção em cultivo convencional, devido aos inúmeros tratamentos fitossanitários, podem não apresentar o mesmo potencial produtivo em um sistema orgânico de produção, onde o uso de tais procedimentos é proibido, com permissão específica da certificadora de, no máximo, $3 \mathrm{~kg}$ de cobre/ha/ano (IBD, 2006).

À medida que se questiona a aplicação de fungicidas sintéticos para o controle de doenças, por seus possíveis efeitos nocivos à saúde e ao meio ambiente, vem crescendo o interesse por sistemas de cultivo agroecológico, como o orgânico, com um grande nicho de mercado a ser explorado. O Brasil é o maior fornecedor de mangas para o mercado europeu, representando $41 \%$ do total das importações em 2008. As mangas estão creditadas a ser o produto que mais cresce no segmento de fruta orgânica tropical (PAY, 2009). Segundo Torres (2010), a manga orgânica também possui melhor aceitabilidade com base no sabor e na coloração. Entretanto, dentre os principais desafios para o setor de produção de orgânicos, estão a necessidade de pesquisas na gestão de produtos orgânicos para solos tropicais, as variedades apropriadas e o treinamento dos produtores (BUAINAIN; BATALHA, 2007)

O objetivo do presente trabalho foi avaliar o comportamento de variedades de manga cultivadas em sistema orgânico frente às doenças oídio, malformação floral e doenças pós-colheita dos frutos.

\section{MATERIAL E MÉTODOS}

O experimento foi realizado em pomar instalado na APTA - Polo Regional Centro-Norte, em Pindorama-SP, temperatura média anual de $22,8^{\circ} \mathrm{C}$, precipitação média anual de $1.390,3 \mathrm{~mm}$ e umidade relativa média anual de $71,6 \%$. Foram utilizadas 17 variedades de manga, cultivadas em sistema orgânico: Alfa, Ataulfo, Beta, Bourbon, Bourbon Vermelha, Espada Ouro de Itaparica, Espada Stahl, IAC 111, Imperial, Lita, Ômega, Palmer, Parvin, Rocha, Rosa, Surpresa e Ubá. As variedades foram enxertadas sobre porta-enxerto da variedade Manila (Carabao). As mudas foram plantadas em $1^{\circ}$ de 
fevereiro de 2007, em delineamento experimental em blocos completos ao acaso, com 17 tratamentos (variedades) e seis repetições (blocos), sendo as parcelas compostas de duas plantas, em espaçamento $8 \times 5 \mathrm{~m}$. Para antracnose, foi feito controle preventivo, com pulverização com hidróxido de cobre (200 g /100 litros de água), no momento em que as plantas emitiram brotações novas.

A incidência de malformação floral foi determinada através da observação visual e contagem das plantas com sintomas da doença em cada variedade, obtendo-se, assim, a porcentagem. Para avaliar a severidade, realizou-se a contagem das inflorescências doentes e sadias, individualmente em cada planta, calculando-se, desta forma, a porcentagem de inflorescências atacadas por planta. Após as avaliações, os ramos doentes sofreram poda drástica e foram retirados da área e posteriormente queimados.

Foi utilizada a escala proposta por Pinto et al. (2004) para a classificação da severidade de malformação floral: muito alta, maior que 50\% de inflorescências doentes; alta, entre 30 e 50\%; média, entre 10 e $30 \%$; baixa, entre 5 e $10 \%$; muito baixa, entre 1 e $5 \%$; e sem incidência, com nenhuma panícula com malformação floral. Para fins de análise estatística, os dados foram transformados em arcoseno $(\mathrm{x} / 100)^{1 / 2}$, e as médias, comparadas pelo teste de Tukey, a $5 \%$ de probabilidade.

A avaliação de oídio foi realizada pela observação dos sintomas em inflorescências jovens. Dez inflorescências foram avaliadas por planta. Para a avaliação, foi utilizada uma escala de notas: 1 - sintomas visíveis em 0 a $25 \%$ da inflorescência; 2 - 25 a $50 \% ; 3$ - 50 a $75 \%$, e 4 - mais de $75 \%$ da inflorescência com sintomas da doença.

$\mathrm{Na}$ caracterização das doenças póscolheita,foram utilizados 15 frutos por variedade, na safra de 2009/2010, e 20 frutos por variedade na safra de 2010/2011, colhidos no estádio de maturação fisiológica “de vez". Após a colheita, os frutos foram transportados até o laboratório e individualizados em bandejas plásticas, onde permaneceram por dez dias, a $25^{\circ} \mathrm{C}$ e $80 \%$ de UR. A severidade (área do fruto) da antracnose foi visualmente avaliada após 1, 4, 7 e 10 dias da colheita dos frutos. Após a obtenção dos dados, foi calculada a área abaixo da curva de progresso da doença (AACPD). Os dados foram analisados por análise de variância, e as médias, comparadas pelo teste de Tukey, ao nível de 5\% de probabilidade.

\section{RESULTADOS E DISCUSSÃO}

A variedade Rosa foi a única a apresentar a totalidade das inflorescências sem malformação floral (Tabela 1). As variedades Surpresa, Espada Stahl, Bourbon, Espada Ouro de Itaparica, Ataulfo e Beta, apesar de não diferirem estatisticamente das demais, apresentaram menor incidência de árvores com a doença.

Quanto à severidade da malformação, a variedade Lita apresentou a maior classificação das variedades estudadas, com mais de $50 \%$ de severidade. As variedades IAC 111 e Ubá, apesar de apresentarem a totalidade das plantas com malformação, tiveram severidade mediana. As variedades Bourbon, Espada Stahl, Ataulfo e Beta, mesmo sem diferir significativamente de outras (Tabela 1), destacaram-se pela severidade muito baixa de malformação floral.

A seleção IAC 111, filha de Surpresa com pai ignorado, é classificada como altamente suscetível à malformação (ROSSETTO, informação pessoal). Porém, no presente trabalho, apesar de 100\% de incidência a severidade foi classificada como média, podendo ser controlada com um manejo adequado de podas. A Embrapa Cerrados lançou a cultivar Alfa, em 1998, como sendo cultivar com baixa incidência de malformação (PINTO et al., 2004), dado observado neste trabalho, com severidade baixa $(6,81 \%)$.

No presente trabalho, a variedade Parvin apresentou alta porcentagem de incidência e severidade da malformação $(87,5 \%$ e 42,20\%, respectivamente). Zaccaro et al. (2007) avaliaram o comportamento de cultivares de manga em relação à malformação pela inoculação de mudas de 15 cultivares e verificaram que as cultivares Palmer, Parvin, Sensation, Van Dyke e Zill apresentaram menor incidência de malformação em condição de inoculação artificial. Esses resultados conflitantes dão apoio ao relato de Kumar et al. (2011), de que a malformação varia conforme o ano, o local e a idade da planta, com uma nítida diferença entre as cultivares.

Iqbal et al. (2011) avaliaram 23.393 inflorescências, representando 40 locais distantes, de oito cultivares monoembriônicos de mangueira no Paquistão, e não verificaram resistência à doença. Segundo os autores, o impacto de uma doença como a malformação simplesmente não pode ser avaliado pela incidência da doença. Ainda, poucas árvores em um ou dois pomares no mesmo local não proveem estimativa correta, portanto os resultados devem ser confirmados através de avaliação de um alto número 
de árvores e inflorescências em diferentes áreas. Como no Brasil a maioria dos pomares comerciais se baseia em uma ou duas variedades, avaliações como as do presente trabalho, com diversas variedades, devem ser feitas periodicamente, se possível em várias regiões, para que os resultados apresentados se tornem mais significativos.

Com relação à infecção por oídio (Tabela 2), a classificação por notas de sintomas na inflorescência mostra que a maior parte das variedades estudadas apresentou comportamento intermediário. Apenas as variedades Omega e Rocha classificaram-se como resistentes.

As variedades Alfa, Beta, Bourbon Vermelha, Espada Stahl, IAC 111 e Surpresa apresentaram sintomas visíveis de oídio entre 25 e $50 \%$ da inflorescência, podendo ser classificadas como moderadas em relação à doença, enquanto maior intensidade de sintomas $(>75 \%)$ foi constatada nas variedades Espada Ouro, Imperial, Lita, Rosa e Ubá (Tabela 2). Em outro estudo de resistência ao oídio com 27 variedades de manga, em pomar que não recebeu tratamento fitossanitário (GALLI et al., 2008), os autores também evidenciaram a maior resistência da variedade Rocha, assim como a elevada suscetibilidade da variedade Rosa. Segundo Ribeiro (2005), a relativa resistência de algumas variedades, como Brasil, Carlota, Oliveira Neto, Tommy Atkins e Keitt, pode estar associada à presença de um pedúnculo com maior diâmetro ou frutos de menor peso, o que permite sua permanência na planta apesar das lesões da doença.

As doenças pós-colheita encontradas nas 17 variedades de manga foram antracnose e podridão peduncular, sendo a incidência da antracnose ao final do período de armazenamento acima de $95 \%$ em todas as variedades. Houve diferença significativa entre as variedades em relação à severidade da antracnose, expressa em AACPD, no decorrer do armazenamento (Tabela 3). As variedades Bourbon Vermelha e Espada Stahl foram menos afetadas em relação às variedades Omega, Surpresa, Ataulfo, Ubá, IAC 111, Imperial, Rocha, Bourbon e Rosa, as três últimas com mais de $10 \%$ de severidade aos sete dias de armazenamento (Figura 1), enquanto Lita, Alfa, Espada Ouro, Beta, Parvin e Palmer apresentaram suscetibilidade intermediária (Tabela 3). Galli et al. (2009) avaliaram, nas mesmas variedades de mangueira cultivadas em sistema orgânico, a severidade de antracnose nas folhas através de uma escala diagramática, atribuindo-se notas aos sintomas, e consideraram como muito suscetíveis à doença as variedades Bourbon, Rocha e Rosa, e resistentes, as variedades IAC 111, Alfa,
Beta e Parvin.

Fischer et al. (2009a) avaliaram a incidência e a severidade das doenças pós-colheita de quatro cultivares de manga e verificaram percentuais de incidência de antracnose de 96,0\%, 84,0\%, 58,0\% e $50,0 \%$, respectivamente, para as cultivares Keitt, Haden, Palmer e Tommy Atkins, resultado semelhante ao presente trabalho quanto à suscetibilidade intermediária de mangas Palmer.

Os sintomas da podridão peduncular foram observados a partir do quarto dia de armazenamento dos frutos (Figura 2), atingindo 32,3\% de incidência na média das variedades, no décimo dia de armazenamento (Tabela 4). As variedades Bourbon Vermelha e Espada Stahl não apresentaram podridão peduncular e, junto com a variedade Bourbon, foram as menos suscetíveis ao final do armazenamento, quando comparadas às variedades Beta, Parvin, IAC 111 e Rocha, com incidência superior a $50 \%$. As demais variedades apresentaram incidência intermediária (17,2-48,0\%), sendo estatisticamente semelhantes entre si (Tabela 4). Dentro do complexo de agentes patogênicos relatados como responsáveis pela podridão peduncular, foram identificados Fusicoccum spp. (46,6\%), Dothiorella spp. (39,3\%) e L. theobromae (14,0\%).

Em estudo das doenças pós-colheita realizado em 2007, também em Pindorama-SP, em pomar sem pulverizações de defensivos, foram observados $100 \%$ de incidência de antracnose em frutos de 15 variedades de manga, após um dia de armazenamento, e $20,8 \%$ de incidência de podridão peduncular aos 10 dias de armazenamento (FISCHER et al., 2009b).

As 17 variedades de manga apresentaram diferenças quanto à suscetibilidade à antracnose $\mathrm{e}$ à podridão peduncular, com destaque para a baixa suscetibilidade de Bourbon Vermelha e Espada Stahl, conforme já observado por Soares et al. (2010) com relação à antracnose. Elevada suscetibilidade das variedades Bourbon e Rosa à antracnose já havia sido relada por Fischer et al. (2009b) e Galli et al. (2009), assim como menor suscetibilidade das variedades Ubá e Palmer. Esses autores também observaram maior resistência da variedade Surpresa em relação à Rosa. No presente estudo, a variedade Rocha foi mais afetada pela antracnose em relação às variedades Ubá, Surpresa e Palmer, enquanto Fischer et al. (2009b) não observaram diferenças significativas entre estas quatro variedades. Com relação à suscetibilidade à podridão peduncular, dados de incidência semelhantes, estatisticamente, entre as variedades Palmer, Ubá, Rosa, Surpresa e Rocha também foram observadas por Fischer et al. (2009b). Informações sobre o comportamento às podridões 
das demais variedades analisadas são inexistentes ou baseadas em informações pouco precisas.

A ocorrência de elevada temperatura e, principalmente, elevada umidade entre a floração e o desenvolvimento dos frutos, como ocorre na região Sudeste, é favorável à antracnose e à podridão peduncular (RIBEIRO, 2005). A antracnose está amplamente disseminada em todas as regiões produtoras de manga no Brasil, embora não cause danos expressivos nas regiões de clima seco, o que tem motivado o plantio de pomares em regiões como as do semiárido nordestino. Já o aumento da incidência da podridão peduncular em várias localidades, como nas áreas irrigadas da região Nordeste, é motivo de grande preocupação.

Os resultados confirmam a importância econômica das doenças pós-colheita em manga, visto que a simples presença dos sintomas desqualifica o fruto para comercialização. A grande ocorrência de podridões sugere a necessidade de um manejo preventivo adequado durante a florada e o desenvolvimento dos frutos, assim como um manejo em pós-colheita, visando a propiciar a redução dessas perdas. No México, onde as principais variedades cultivadas em sistema orgânico são Tommy Atkins, Kent e Ataulfo, em adição às pulverizações fitossanitárias preventivas, adota-se em pós-colheita o tratamento hidrotérmico, voltado principalmente para o controle da antracnose (MEDINA-URRUTIA et al., 2011).
No presente experimento, quando se confrontam os resultados obtidos para as doenças avaliadas, em conjunto, verifica-se que as variedades apresentam comportamentos bastante variados. Por exemplo, a variedade Rosa, que não apresentou malformação floral, por outro lado, apresentou alta incidência de oídio e antracnose, assim como a Bourbon. A variedade Lita, que apresentou maior severidade de malformação floral e oídio, por outro lado, apresentou baixa severidade de antracnose e incidência intermediária de podridão peduncular. A variedade Rocha, considerada como resistente ao oídio, apresentou alta incidência de antracnose e a maior incidência de podridão peduncular do experimento.

Já as variedades Bourbon Vermelha e Espada Stahl, que não apresentaram podridão peduncular e menor suscetibilidade de antracnose, apresentaram, respectivamente, severidade à malformação floral média e muito baixa, e baixa incidência de oídio. Essas variedades merecem destaque no experimento, podendo ser boa opção para o cultivo orgânico. Merecem destaque, também, as variedades que apresentaram comportamento intermediário quanto à suscetibilidade a essas doenças, como a Alfa e a Beta, que apresentaram severidade baixa e muito baixa à malformação floral, respectivamente; baixa incidência de oídio e suscetibilidade intermediária à antracnose e à podridão peduncular.

TABELA 1 - Médias em porcentagem de incidência e severidade da malformação floral em variedades de mangueira.

\begin{tabular}{|c|c|c|c|}
\hline \multirow{2}{*}{ Variedades } & Incidência & Severidade & \multirow[b]{3}{*}{ Média $^{2}$} \\
\hline & & & \\
\hline IAC 111 & $100 a^{1}$ & 17,54abcd & \\
\hline Lita & 100a & $58,05 \mathrm{a}$ & Muito alta \\
\hline Omega & $100 \mathrm{a}$ & 20,97abcd & Média \\
\hline Rocha & $100 \mathrm{a}$ & $22,27 \mathrm{abc}$ & Média \\
\hline Ubá & $100 a$ & $13,96 \mathrm{bcd}$ & Média \\
\hline Bourbon Vermelha & $87,5 \mathrm{a}$ & 17,20 bcd & Média \\
\hline Parvin & $87,5 \mathrm{a}$ & $42,20 \mathrm{ab}$ & Alta \\
\hline Imperial & $75 a$ & $16,30 \mathrm{bcd}$ & Média \\
\hline Palmer & $75 a$ & 26,69abcd & Média \\
\hline Alfa & $75 a$ & $6,81 \mathrm{~cd}$ & Baixa \\
\hline Surpresa & $62,5 \mathrm{ab}$ & 9,90 bcd & Baixa \\
\hline Espada Stahl & $50 \mathrm{ab}$ & 3,47 cd & Muito baixa \\
\hline Bourbon & $50 a b$ & 1,11 cd & Muito baixa \\
\hline Espada Ouro & 50ab & 9,73 & Baixa \\
\hline Ataulfo & $37,5 \mathrm{ab}$ & 3,95 & Muito baixa \\
\hline Beta & $37,5 \mathrm{ab}$ & $1,70 \mathrm{~cd}$ & Muito baixa \\
\hline Rosa & $0 \mathrm{~b}$ & 0 & Sem incidência \\
\hline CV (\%) & 35,08 & 53,91 & \\
\hline
\end{tabular}

\footnotetext{
${ }^{1}$ Médias seguidas pela mesma letra na coluna não diferem entre si, pelo teste de Tukey, a 5\% de probabilidade. Análise estatística com os dados transformados em arco-seno $(\mathrm{x} / 100)^{1 / 2}$.

${ }^{2}$ Severidade de malformação floral baseada em escala de classificação: muito alta, maior que $50 \%$ de inflorescências doentes; alta, entre 30 e 50\%; média, entre 10 e 30\%; baixa, entre 5 e $10 \%$; muito baixa, entre 1 e $5 \%$; e sem incidência, com nenhuma panícula com malformação floral.
} 
TABELA 2 - Classificação das variedades com relação à presença de oídio.

\begin{tabular}{ll}
\hline Notas & \multicolumn{1}{c}{ Variedades } \\
\hline $1-0$ a $25 \%$ de sintomas & Rocha e Omega \\
2- 25 a $50 \%$ de sintomas & Alfa, Beta, B. Vermelha, Espada Stahl, IAC 111, Surpresa \\
3- 50 a $75 \%$ de sintomas & Ataulfo, Bourbon, Palmer, Parvin \\
$4-\quad>75 \%$ de sintomas & Espada Ouro, Imperial, Lita, Rosa, Ubá \\
\hline
\end{tabular}

TABELA 3 - Área abaixo da curva de progresso da doença (AACPD) obtida a partir de quatro avaliações da severidade da antracnose durante os dez dias de armazenamento a $25^{\circ} \mathrm{C}$, em variedades de manga cultivadas em sistema orgânico.

\begin{tabular}{lc}
\hline \multicolumn{1}{c}{ Variedades } & AACPD- antracnose ${ }^{1}$ \\
\hline Bourbon vermelha & $2,2 \mathrm{a}^{2}$ \\
Espada Stahl & $5,6 \mathrm{a}$ \\
Lita & $11,0 \mathrm{ab}$ \\
Alfa & $20,7 \mathrm{ab}$ \\
Espada ouro & $23,0 \mathrm{ab}$ \\
Beta & $23,3 \mathrm{ab}$ \\
Parvin & $26,0 \mathrm{abc}$ \\
Palmer & $28,8 \mathrm{abc}$ \\
Omega & $36,8 \mathrm{bc}$ \\
Surpresa & $37,9 \mathrm{bc}$ \\
Ataulfo & $44,1 \mathrm{bc}$ \\
Ubá & $49,5 \mathrm{bc}$ \\
IAC 111 & $72,0 \mathrm{~cd}$ \\
Imperial & $75,5 \mathrm{~cd}$ \\
Rocha & $141,0 \mathrm{de}$ \\
Bourbon & $152,6 \mathrm{e}$ \\
Rosa & $167,8 \mathrm{e}$ \\
\hline CV $(\%)$ & 21,4 \\
\hline
\end{tabular}

Média de 15 frutos/variedade em 2009 e 20 frutos/variedade em 2010.

${ }^{2}$ Dados seguidos pela mesma letra minúscula na coluna não diferem entre si, a nível de $5 \%$, pelo teste de Tukey. Análise estatística com os dados transformados em raiz de $\mathrm{x}$.

TABELA 4 - Incidência da podridão peduncular em variedades de manga cultivadas em sistema orgânico, aos dez dias de armazenamento a $25^{\circ} \mathrm{C}$.

\begin{tabular}{lc}
\hline \multicolumn{1}{c}{ Variedades } & Incidência $(\%)$ de podridão peduncular ${ }^{1}$ \\
\hline Bourbon Vermelha & $0,0 \mathrm{a}^{2}$ \\
Espada Stahl & $0,0 \mathrm{a}$ \\
Bourbon & $12,5 \mathrm{ab}$ \\
Palmer & $17,2 \mathrm{abc}$ \\
Omega & $17,4 \mathrm{abc}$ \\
Ubá & $28,0 \mathrm{bc}$ \\
Imperial & $30,3 \mathrm{bc}$ \\
Rosa & $31,0 \mathrm{bc}$ \\
Lita & $33,3 \mathrm{bc}$ \\
Ataulfo & $37,5 \mathrm{bc}$ \\
Alfa & $40,0 \mathrm{bc}$ \\
Surpresa & $44,2 \mathrm{bc}$ \\
Espada ouro & $48,0 \mathrm{bc}$ \\
Beta & $51,0 \mathrm{c}$ \\
Parvin & $51,0 \mathrm{c}$ \\
IAC 111 & $52,6 \mathrm{c}$ \\
Rocha & $54,5 \mathrm{c}$ \\
Média & 32,3 \\
\hline
\end{tabular}

${ }^{1}$ Média de 15 frutos/variedade em 2009 e 20 frutos/variedade em 2010.

${ }^{2}$ Dados seguidos pela mesma letra minúscula na coluna não diferem entre si, em nível de $5 \%$, pelo teste não paramétrico de comparação de múltiplas proporções (ZAR, 1999). 

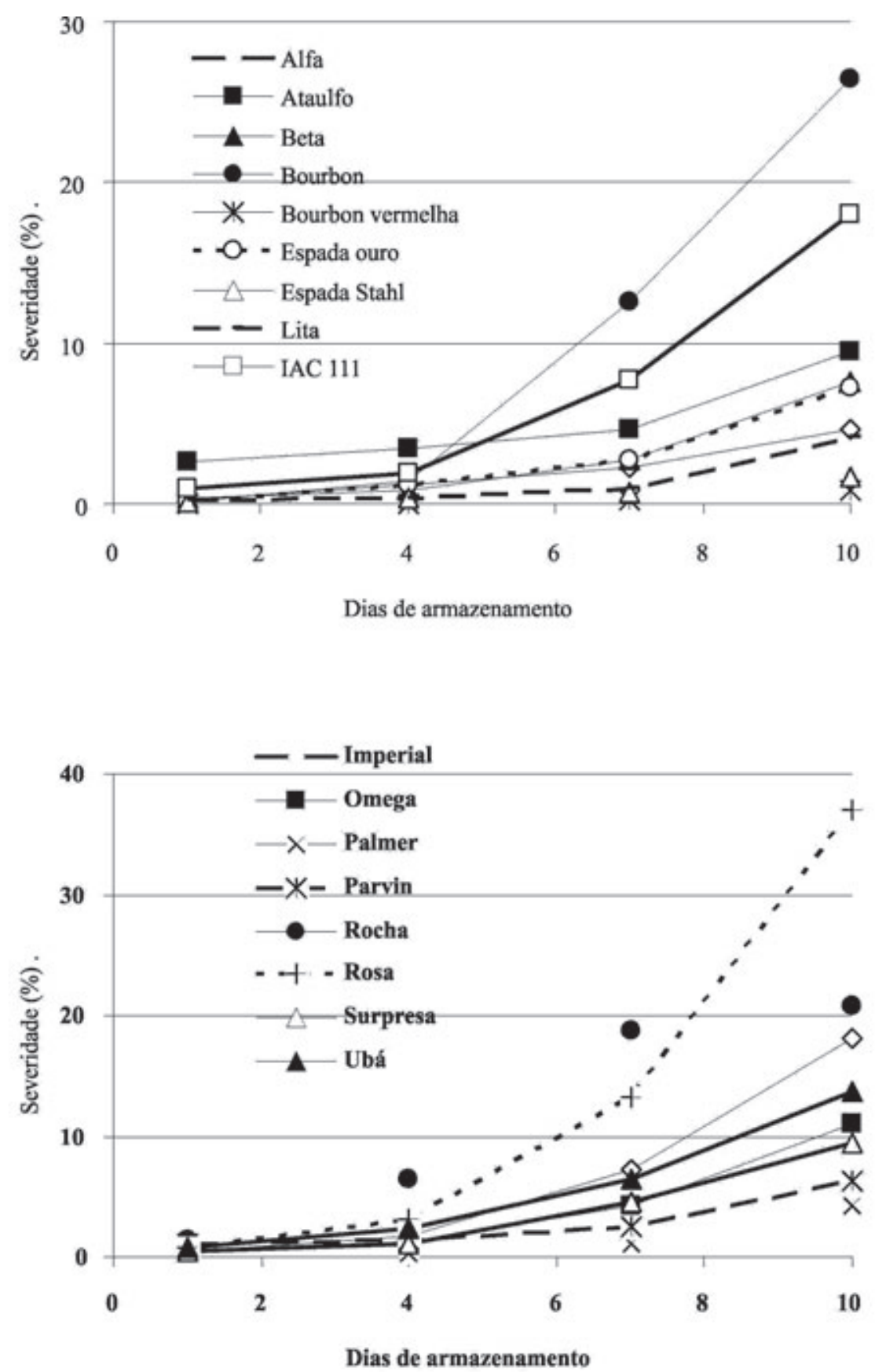

FIGURA 1 - Severidade da antracnose em frutos de variedades de mangas cultivadas em sistema orgânico, durante dez dias de armazenamento a $25^{\circ} \mathrm{C}$. 


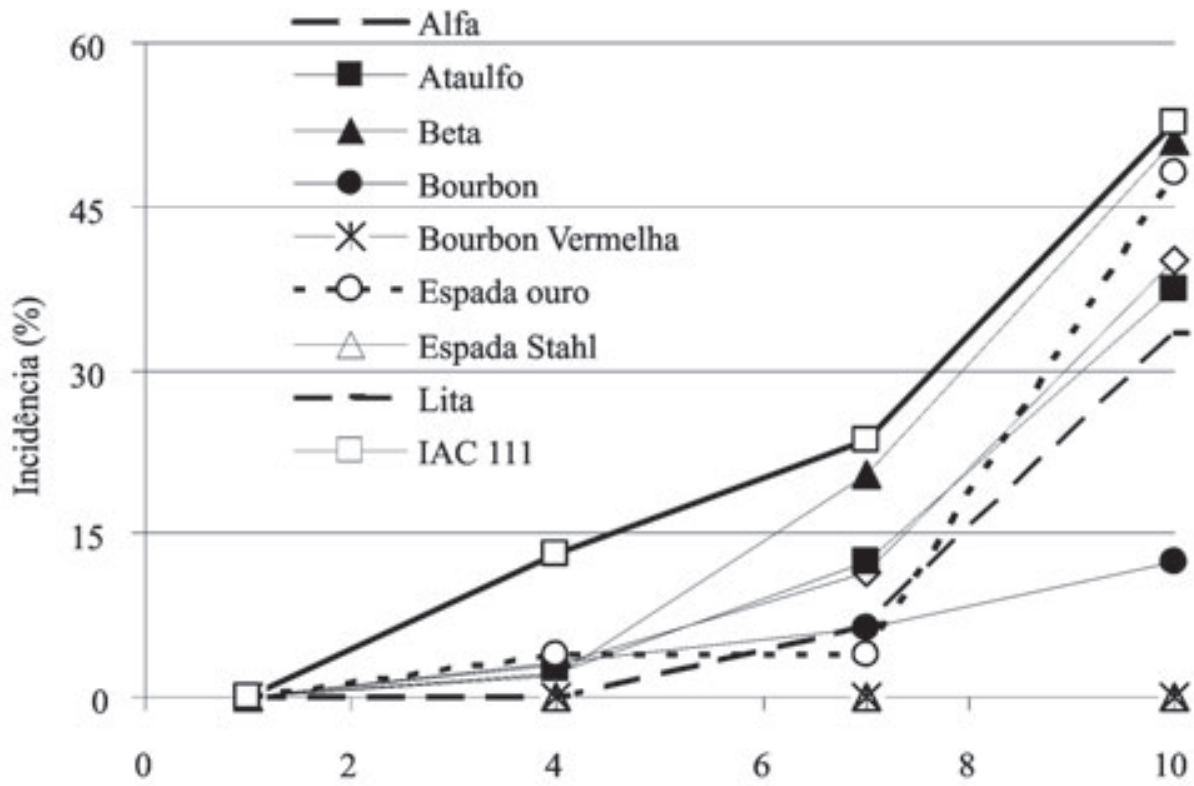

Dias de armazenamento

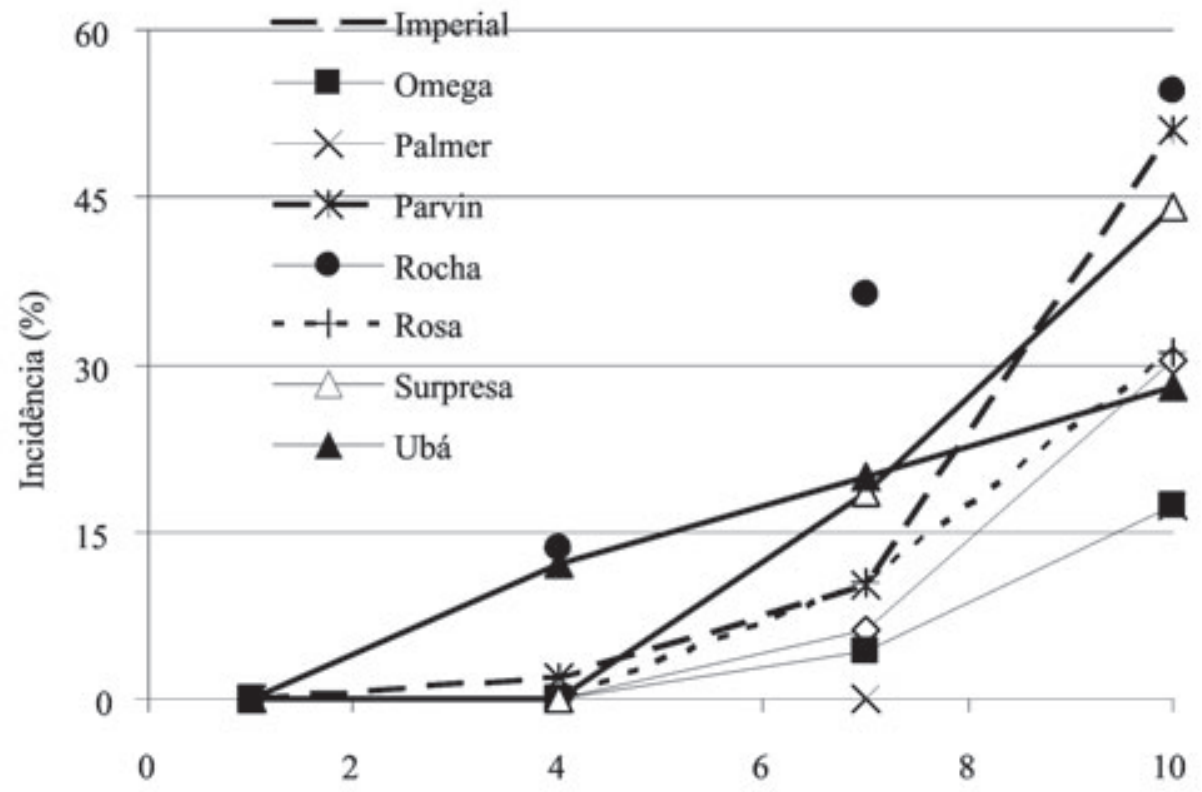

Dias de armazenamento

FIGURA 2 - Incidência (\%) da podridão peduncular em variedades de mangas cultivadas em sistema orgânico, durante dez dias de armazenamento a $25^{\circ} \mathrm{C}$. 


\section{CONCLUSÕES}

1-As 17 variedades de manga cultivadas em sistema orgânico apresentaram diferenças de comportamento em relação às doenças oídio, malformação floral e doenças pós-colheita.

2-As variedades Bourbon Vermelha e Espada Stahl destacaram-se por não apresentar podridão peduncular e apresentarem menor severidade de antracnose, baixa ocorrência de oídio e média e muito baixa severidade da malformação floral, respectivamente, podendo ser melhor exploradas pelos produtores orgânicos.

3-A variedade Rosa não apresentou malformação floral, e as variedades Rocha e Omega foram as menos afetadas pelo oídio, podendo, em locais onde estas doenças são limitantes, ser indicadas para o cultivo.

\section{AGRADECIMENTOS} projeto.

À FAPESP, pelo auxílio financeiro a este

\section{REFERÊNCIAS}

ANGEL, N.D.; RAMOS, M.A.; ORTIZ, D.T.; SÃO JOSÉ, A.P. Enfermidades Del mango. In: OLIVEIRA, J.M.A.; TERAO, D.; DANTAS, S.A.F.; TAVARES, S.C.C.H. (Ed.). Patologia pós-colheita: frutas, olerícolas e ornamentais tropicais. Brasília: Embrapa Informações Tecnológicas, 2006. p.733774.

BUAINAIN, A.M.; BATALHA, M.O. Cadeia produtiva de produtos orgânicos. Brasília: MAPA, 2007. v.5. 108p.

FISCHER, I.H.; ARRUDA, M.C.; ALMEIDA, A.M.; GALLI, J.A.; BERTANI, R.M.A.; JERÔNIMO, E.M. Doenças pós-colheita em variedades de manga cultivadas em Pindorama, São Paulo. Revista Brasileira de Fruticultura, Jaboticabal, v.31, n.2, p. 352-359, 2009a.

FISCHER, I.H.; ARRUDA, M.C.; ALMEIDA, A.M.; MONTES, S.M.N.M.; JERÔNIMO, E.M.; SIMIONATO, E.M.R.S.; BERTANI, R.M.A. Doenças e características físicas e químicas póscolheita em manga. Semina: Ciências Agrárias, Londrina, v.30, n.1, p. 107-116, 2009b.
GALLI, J.A.; SILVEIRA, L.C.P.; MICHELOTTO, M.D.; MARTINS, A.L.M. Powdery mildew (Oidium mangiferae BERT.) infection in mango varieties. Bioscience Journal, Uberlândia, v.24, n.2, p.4346, 2008

GALLI, J.A.; SILVEIRA, L.C.P.; MICHELOTTO, M.D.; MARTINS, A.L.M. Avaliação da incidência de antracnose, do desempenho e estado nutricional de variedades de mangueira, para cultivo orgânico, na região Centro-Norte do Estado de São Paulo. Revista Brasileira de Fruticultura, Jaboticabal, v.31, n.3, p.701-709, 2009.

INSTITUTO BIODINÂMICO. Diretrizes para o padrão de qualidade Orgânico Instituto Biodinâmico. 13. ed. Botucatu: IBD, 2006. 87p.

IQBAL, Z.; AKHTAR, N.; GHAZANFAR, M.U.; SHEHZAD, S.M.; AHMAD, S.; ASIF, M.; YASIN, M.; PERVEZ, M.A.; DASTI, A.A.; SALEEM, A. Management of mango malformation through physical alteration and chemical spray. African Journal of Agricultural Research, Lagos, v.6, n.7, p.1897-1901, 2011.

KAVATI, R. Manejo da parte aérea da mangueira. In: ROZANE, D.E.; DAREZZO, R.J.; AGUIAR, R.L.; AGUILERA, G.H.A.; ZAMBOLIM, L. Manga: produção integrada, industrialização e comercialização. Viçosa: UFV, 2004. p.303-320.

KUMAR, J. MISRA, A.K.; MODI, D.R. Current status of mango malformation in India. Asian Journal of Plant Sciences, Bholakpur, v. 10, n.1, p.1-23, 2011.

LIMA, C.S.; PFENNING, L.H.; COSTA, S.S.; CAMPOS, M.A.; LESLIE, J. F. A new Fusarium lineage within the Gibberella fujikuroi species complex is the main causal agent of mango malformation disease in Brazil. Plant Pathology, St. Paul, v.58, p.33-42, 2009.

MARASAS, W.F.O.; PLOETZ, R.C.; WINGFIELD, M.J.; WINGFIELD, B.D.; STEENKAMP, E.T. Mango malformation disease and the associated Fusarium species. Phytopathology, St. Paul, v.96, p.667-672, 2006. 
MEDINA-URRUTIA, V.M.; VÁZQUEZ-GARCÍA, M.; VIRGEN-CALLEROS, G. Organic mango production in Mexico: status of orchard management. Acta Horticulturae, The Hague, v.894, p.255-263, 2011.

NOFAL, M.A.; HAGGA, W.A. Integrated management of powdery mildew of mango in Egypt. Crop Protection, Kidlington, v.25, p.480-486, 2006.

PAY, E. The market for organic and fair-trade mangoes and pineapples. FAO: Rome, 2009. 23p. Disponível em: <http://www.fao.org/fileadmin/ templates/organicexports/docs/Market_Organic FT_Pineapple_Mango.pdf $>$ Acesso em: $01 \mathrm{dez}$. 2011.

PINTO, A.C. de Q.; RAMOS, V.H.V.; DIAS, J.N. Avaliação de cultivares e seleções híbridas de manga em áreas de cerrado. Planaltina: Embrapa Cerrados, 2004. 20p. (Boletim de Pesquisa e Desenvolvimento, 140).

RIBEIRO, I.J.A. Doenças da mangueira (Mangifera indica L.). In: KIMATI, H.; AMORIM, A.; REZENDE, J.A.M.; BERGAMIN-FILHO, A.; CAMARGO, L.E.A. Manual de fitopatologia: doenças das plantas cultivadas. São Paulo: Agronômica Ceres, 2005. v.2, p.457-465.
SOARES, N.B.; MARTINS, A.L.M.; RIBEIRO, I.J.A.; GALLI, J.A.; VEIGA, R.F.A.; CARVALHO, C.R.L.; NARITA, N.; ROSSETTO, C.J. Recursos genéticos de mangueira na Agência Paulista de Tecnologia dos Agronegócios. Campinas: Instituto Agronômico, 2010. 23 p. (Documentos IAC, 98).

TORRES, L.B.V. Qualidade e conservação póscolheita de mangas oriundas de sistemas de produção orgânica ou integrada. 2010. 239 f. Tese (Doutorado) - Centro de Ciências Agrárias, Universidade Federal da Paraíba, Areia, 2010.

ZACCARO, R.P.; DONADIO, L.C.; LEMOS, E.G.M.; PERECIN, D. Comportamento de cultivares de manga (Mangifera indica L.) em relação à malformação. Revista Brasileira de Fruticultura, Jaboticabal, v.29, n.1, p.115-119, 2007.

ZAMBOLIM, L.; JUNQUEIRA, N.T.V. Manejo Integrado de doenças da mangueira.In: ROZANE, D.E.; DAREZZO, R.J.; AGUIAR, R.L.; AGUILERA, G.H.A.; ZAMBOLIM, L. Manga: produção integrada, industrialização e comercialização. Viçosa: UFV, 2004. p.377-408.

YOUSSEF, S.A.; MAYMON, M; ZVEIBIL, A.; KLEIN-GUETA, D.; SZTEJNBERG, A.; SHALABY, A.A.; FREEMAN, S. Epidemiological aspects of mango malformation disease caused by Fusarium mangiferae and source of infection in seedlings cultivated in orchards in Egypt. Plant Pathology, St. Paul, v.56, p. 257-263, 2007. 